\title{
Review
}

Pharmacology

\section{Advances in Drug Development for Parkinson's Disease: Present Status}

\author{
Dibbanti Harikrishna Reddy Shubham Misra Bikash Medhi \\ Department of Pharmacology, Postgraduate Institute of Medical Education and Research, Chandigarh, India
}

\section{Key Words}

Parkinson's disease - Motor disorder - Clinical trials · Phase I. Phase II · Phase III

\begin{abstract}
The major hallmark of Parkinson's disease (PD) is the progressive loss of dopaminergic neurons in the substantia nigra pars compacta, leading to the characteristic motor symptoms of resting tremors, bradykinesia and rigidity. Research in the field of PD therapy has been partly successful in terms of developing symptomatic treatments, but it also experienced several failures with regard to developing diseasemodifying therapies. According to the definition of the Committee to Identify Neuroprotective Agents for Parkinson's, neuroprotection would be any intervention that favorably influences the disease process or underlying pathogenesis to produce enduring benefits for patients. A development of effective neuroprotective therapies resulting in clinically meaningful results is hampered by several factors in all research stages. Novel solutions might be offered by an evaluation of new targets throughout clinical studies, therapies emerging from drug repositioning approaches, multitarget approaches and network pharmacology. Several promising randomized controlled trials are in progress, and the in-
\end{abstract}

creased collaboration between pharmaceutical companies and basic and clinical researchers has the potential to bring us closer to developing an optimum pharmaceutical approach for the treatment of PD. The aim of the present review is to give an overview of the neuroprotective agents and their targets currently investigated for the treatment of PD in phase I-III clinical trials.

(c) 2014 S. Karger AG, Basel

\section{Introduction}

Parkinson's disease (PD) is the second most common movement disorder among neurodegenerative diseases [1], first described by James Parkinson in an essay entitled 'An essay on the shaking palsy' in 1817 [2]. Later, the famous French neurologist Jean-Martin Charcot further described the syndrome in the late 1800s. In fact, age is the most important risk factor for PD: worldwide, approximately $1-2 \%$ of the population older than 65 years suffer from this slowly progressive degenerative disease [3]. The majority of PD cases are idiopathic (90-95\%) with no specific known cause, and the remaining ones are familial forms (5-10\%). The genes that are thought to be involved in familial PD are

\section{KARGER}

E-Mail karger@karger.com www.karger.com/pha (c) 2014 S. Karger AG, Base

0031-7012/14/0936-0260\$39.50/0
Dr. Bikash Medhi

Department of Pharmacology

Postgraduate Institute of Medical Education and Research

Chandigarh 160012 (India)

E-Maildrbikashus@yahoo.com 


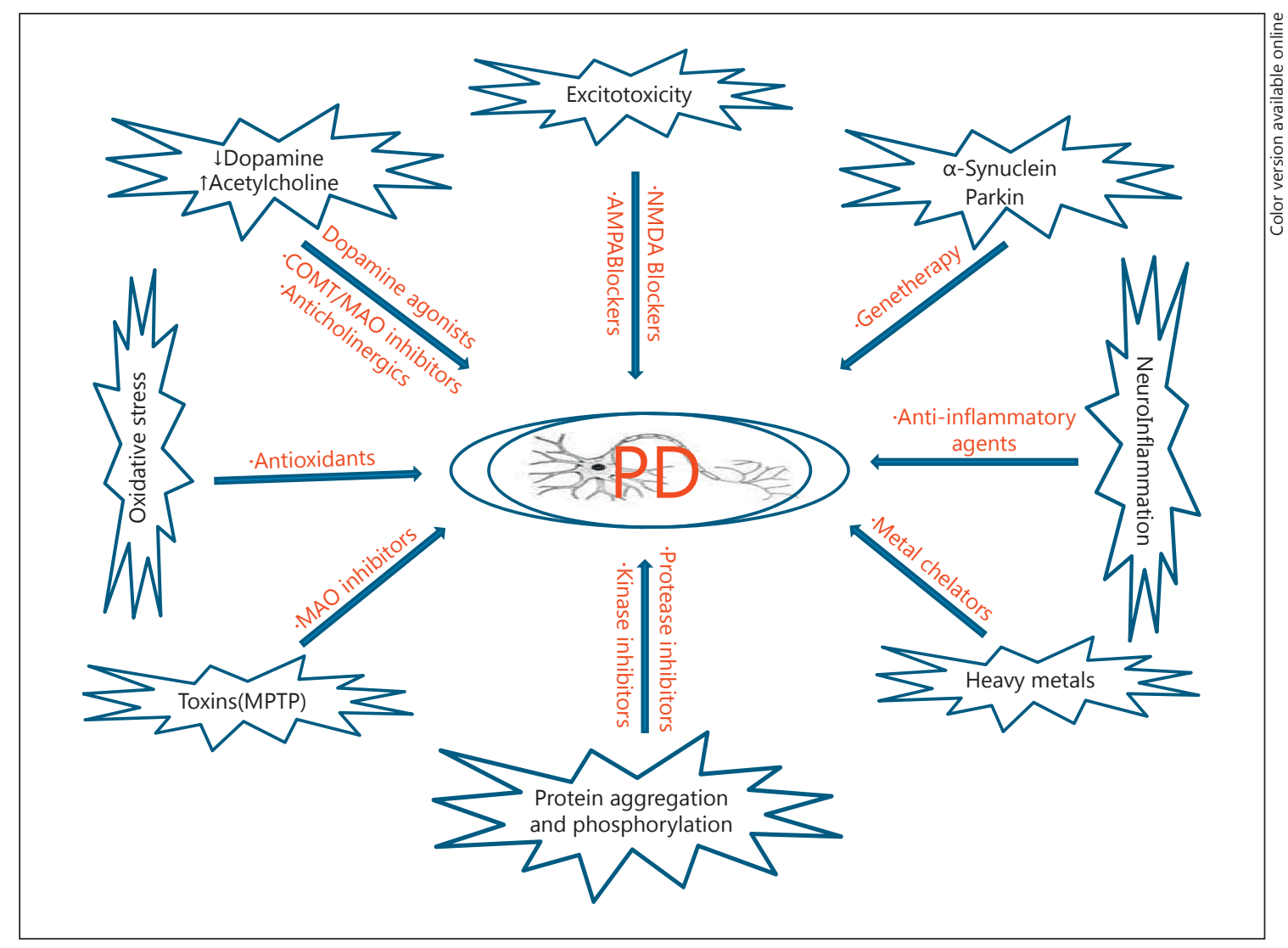

Fig. 1. Pharmacotherapeutic targets in PD. PD is a multifaceted disease involving the activation of several cellular pathways in dopaminergic neurons. These pathways include MPTP toxicity, alterations in neurotransmitter levels, oxidative stress, glutamate ex- citotoxicity, mitochondrial dysfunction, neuroinflammation, alterations in gene regulation, protein aggregation and heavy metal poisoning. These mechanisms share overlapping and redundant features and cause injury to the neurons. a-synuclein, parkin, DJ-1, PINK-1, LRRK2, UCH-L1, ATP13A2 and HTRA2 $[4,5]$. Clinically, PD is characterized by motor abnormalities including bradykinesia (especially having difficulties in initiating movement), tremor (pill-rolling movement of the forearm) and muscular rigidity with secondary manifestations such as defective posture, gait impairment, mask-like face and sialorrhea [6]. Nonmotor symptoms are depression, constipation, pain, genitourinary problems, sleep disorders, emotional changes, speech changes, dementia, cognitive problems, muscle cramps, dystonia, fatigue and loss of energy [7].

The main pathological hallmark of PD is the loss of dopaminergic neurons in the substantia nigra pars compacta, which leads to the depletion of dopamine in the striatum and accumulation of $\alpha$-synuclein protein in the brain in the form of Lewy bodies. The role of these Lewy bodies in pathogenesis remains unknown, but it was dis- covered that misfolded $\alpha$-synuclein is a major component of the radiating filaments in PD [1]. Various other pathogenic mechanisms that are implicated in dopaminergic cell death in PD are oxidative stress, excitotoxicity, mitochondrial dysfunction, neuroinflammation, protein aggregation, phosphorylation, genetic defects and toxins (fig.1) [8-10].

Although levodopa still remains the standard drug for symptomatic treatment in reducing the motor symptoms of $\mathrm{PD}$, its long-term use is associated with the development of potentially disabling motor complications including response oscillations as well as levodopa-induced dyskinesias (LID), affecting approximately $30-35 \%$ of patients after just 2 years of exposure to levodopa. In order to avoid the complications arising with levodopa, many new neuroprotective agents are under investigation, using different novel mechanisms of actions [11]. 
The purpose of this review is to provide details of the current status of drug development for PD. We focus on the drugs that have entered clinical phases, mainly phases II and III, but we include a brief overview of the drugs in phase I trials.

\section{Methods}

The screening of papers was conducted online by searching various databases such as Medline (PubMed) and the Cochrane database until June 2013. PubMed was searched using the following key words:

- Parkinson's disease and clinical trials for the years 2009-2013

- Motor symptoms and clinical trials for the years 2009-2013

- The chemical names of every compound mentioned in any article on new drugs for PD since 2009

ClinicalTrials.gov was searched using the key words:

- Parkinson's disease

- Motor disorder

- Parkinson's disease phase I, phase II, phase III

Clinical trials included all trials using the key words randomized, placebo-controlled, double-blind and parallel-group design.

\section{Phase I Trials}

Phase I trials are the first stage of testing drugs in human subjects. Normally, a small group of 20-100 healthy volunteers is recruited. This phase is designed to assess the safety, tolerability, pharmacokinetics and pharmacodynamics of a drug. As it takes several years for a compound to come into the market from phase I clinical trials and the probability of success is quite low, it is meaningless to give detailed descriptions of individual compounds. Table 1 provides a brief overview of drugs for PD that are in phase I trials.

\section{Phase II Trials}

Once the dose or range of doses has been determined in phase I trials, the next aim is to evaluate whether the drug has any biological activity or not. Phase II trials are performed on larger groups (100-300 individuals) and are designed to assess how well the drug works as well as to continue phase I safety assessments in a larger group of volunteers and patients. Genetic testing is common, particularly if there is evidence of variations in metabolic rate (table 2).

\section{GM1 Ganglioside (Sygen)}

GM1 (monosialotetrahexosylganglioside), the 'prototypical' ganglioside, is a member of the ganglio-series of gangliosides which contain one sialic acid residue. GM1 ganglioside is normally found in the brain and is a normal part of the outer covering or membrane of nerve cells. GM1 has important physiological effects such as impacting neuronal plasticity, repair mechanisms and the release of neurotrophins in the brain. In addition, GM1 has antiexcitotoxic properties. Various studies on nonhuman primates have shown that treatment with GM1 ganglioside increased striatal dopamine levels and alleviated the parkinsonian symptoms $[12,13]$.

A phase II trial was designed to examine the extent to which GM1 ganglioside can improve symptoms, delay disease progression and perhaps partly restore damaged brain cells in PD patients. In addition to studying clinical measures of motor and cognitive functioning, the investigators used PET scanning to image the brain and the dopamine nerve endings in a subgroup of patients. Patients with mild-to-moderate idiopathic PD were divided into two groups. One group received GM1 for 24 weeks and the other group placebo. The study has been completed, and GM1 showed a potential role in decreasing motor symptoms and slowed the progression of disease in the PD patients [14].

\section{ADX48621 (Dipraglurant)}

Dipraglurant is a novel, small, orally administered molecule which inhibits the metabotropic glutamate receptor 5 (mGluR5) and has the potential to be used in combination with levodopa or dopamine agonists for the treatment of PD. After the successful completion of two phase I studies of ADX48621 in 36 healthy subjects, in which it was shown that the drug was safe and well tolerated [15], Addex Pharma S.A. started a phase II study to evaluate the safety and tolerability of ADX48621 in PD patients. This was the first study of ADX48621 in male and female PD patients with LID. It was a 4-week doubleblind placebo-controlled trial with a dose titration from $50 \mathrm{mg}$ once daily up to $100 \mathrm{mg} 3$ times daily at the start of week 4 . Safety and tolerability were assessed by adverse event inquiry, heart rate and blood pressure measurements and 12-lead ECG as well as hematology and biochemistry testing. Efficacy assessments included the Abnormal Involuntary Movement Scale (AIMS), the Unified Parkinson's Disease Rating Scale (UPDRS), patient PD symptom diaries, the Hospital Anxiety and Depression Scale (HADS) and the Patient and Clinician Global Impression of Change in PD and dyskinesia (PGIC and CGIC). The study has been completed. ADX48621 was well tolerated and effective and significantly advanced the treatment of PD [16]. 
Table 1. Drugs in phase I clinical trials for the treatment of PD

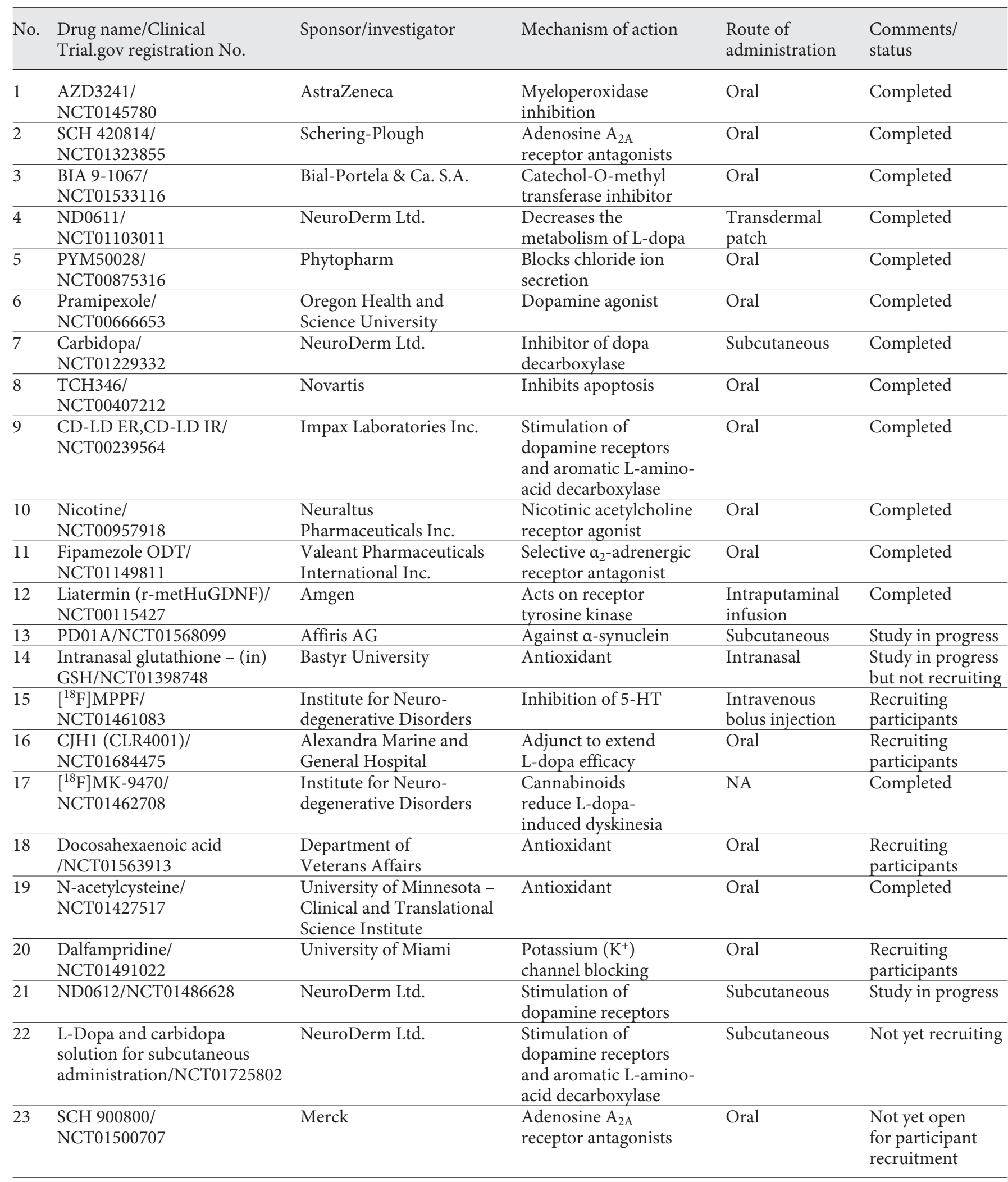


Table 2. Drugs in phase II clinical trials for the treatment of PD

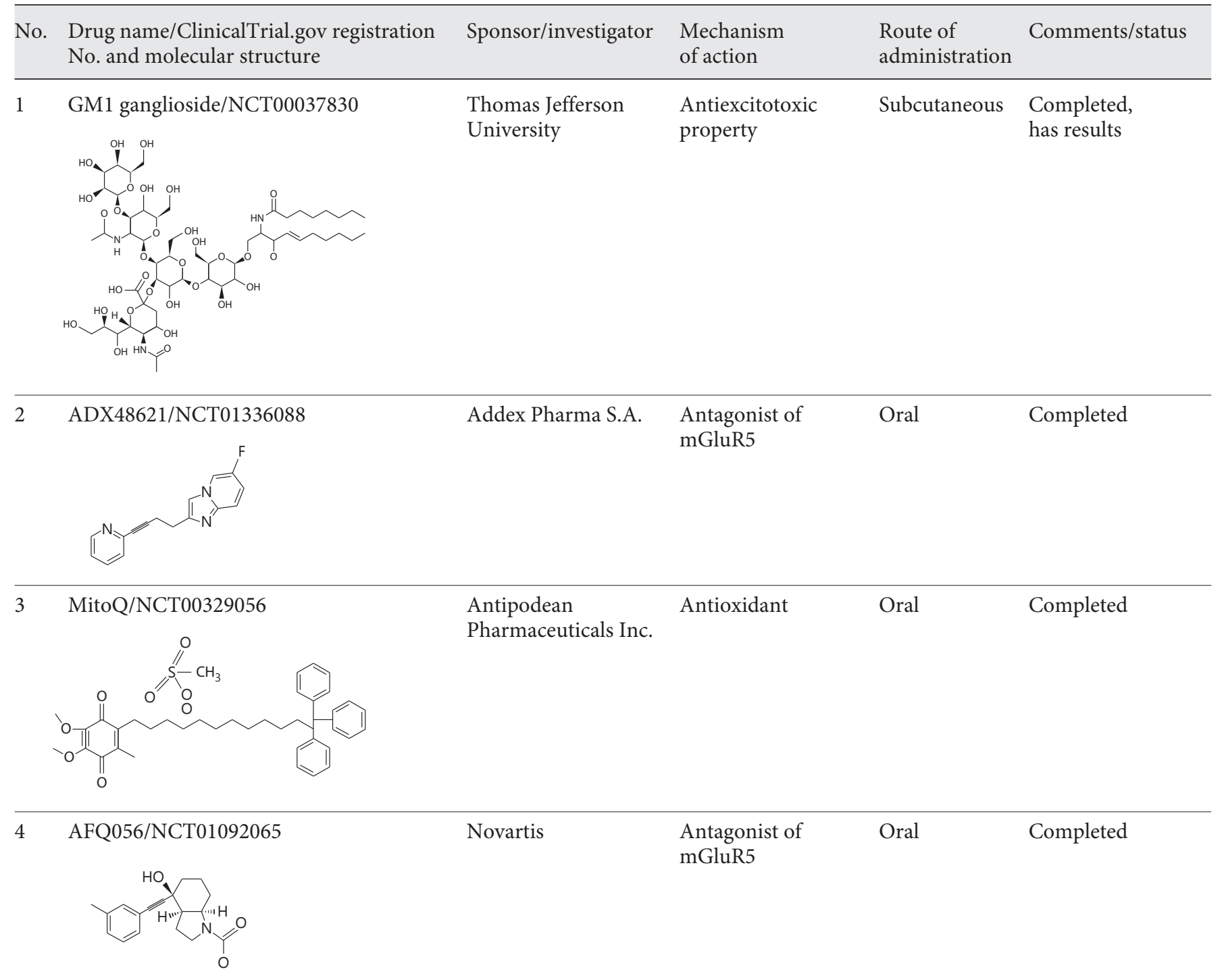

\begin{tabular}{|c|c|c|c|c|c|}
\hline 5 & BIIB014/NCT00442780 & Biogen Idec & $\begin{array}{l}\text { Adenosine } \mathrm{A}_{2 \mathrm{~A}} \\
\text { receptor antagonists }\end{array}$ & Oral & Completed \\
\hline 6 & SR57667B/NCT00220272 & Sanofi & $\begin{array}{l}\text { Acetylcholinesterase } \\
\text { inhibition and } \\
\text { impairment of } \\
\beta \text {-amyloid formation }\end{array}$ & NA & Completed \\
\hline
\end{tabular}


Table 2 (continued)

\begin{tabular}{|c|c|c|c|c|c|}
\hline No. & $\begin{array}{l}\text { Drug name/ClinicalTrial.gov registration } \\
\text { No. and molecular structure }\end{array}$ & Sponsor/investigator & $\begin{array}{l}\text { Mechanism } \\
\text { of action }\end{array}$ & $\begin{array}{l}\text { Route of } \\
\text { administration }\end{array}$ & Comments/status \\
\hline 7 & Pioglitazone/NCT01280123 & $\begin{array}{l}\text { University of } \\
\text { Rochester }\end{array}$ & $\begin{array}{l}\text { Ligands } \\
\text { for PPAR }\end{array}$ & Oral & Not recruiting \\
\hline 8 & CEP-1347/NCT00040404 & Cephalon & $\begin{array}{l}\text { Antiapoptotic } \\
\text { drug }\end{array}$ & Oral & $\begin{array}{l}\text { Terminated due } \\
\text { to adverse events }\end{array}$ \\
\hline 9 & Topiramate/NCT00296959 & $\begin{array}{l}\text { University Health } \\
\text { Network, Toronto }\end{array}$ & $\begin{array}{l}\text { AMPA, glutamate } \\
\text { antagonist }\end{array}$ & Oral & $\begin{array}{l}\text { Terminated due } \\
\text { to slow recruitment }\end{array}$ \\
\hline 10 & Pardoprunox/NCT00903838 & Abbott Products & $\begin{array}{l}\text { Dopamine } \\
\text { partial } \mathrm{D}_{2} / \mathrm{D}_{3} \\
\text { agonist }\end{array}$ & Oral & $\begin{array}{l}\text { Terminated due } \\
\text { to strategic } \\
\text { considerations }\end{array}$ \\
\hline
\end{tabular}

\section{MitoQ}

MitoQ is an orally active antioxidant that has the ability to target mitochondrial dysfunction. It was tested in a randomized double-blind trial in which 120 participants with untreated early onset of PD had been enrolled. The participants were randomized to receive one of three treatments: $40 \mathrm{mg}$ of MitoQ tablets, $80 \mathrm{mg}$ of MitoQ tablets or placebo. They were assessed after 1, 2, 3, 6, 9 and 12 months of treatment, and again 28 days after the last dose. The effectiveness of the trial drug was measured by the UPDRS. The safety of the trial drug was monitored via regular participant examinations, blood tests, ECG and collecting information on adverse events. This phase II trial has been completed, and it showed that MitoQ was effective and well tolerated in early-onset PD patients; the drug is currently prepared for phase III studies [17].

Advances in Drug Development for PD:

Present Status

\section{AFQ056 (Mavoglurant)}

Mavoglurant exerts its effect as an antagonist of mGluR5. A preclinical study conducted on 6 Macaca fascicularis 1-methyl-4-phenyl-1,2,3,6-tetrahydropyridine (MPTP) monkeys had shown that the administration of AFQ056 $1 \mathrm{~h}$ prior to the administration of levodopa significantly reduced the dyskinesias and increased the antiparkinsonian effect [18].

The following phase II double-blind placebo-controlled randomized multicenter study was designed to determine whether AFQ056 is safe and effective or whether it can increase the therapeutic window of levodopa in patients whose control of their PD symptoms was limited by the development of dyskinesia induced by use of levodopa. The primary outcome measures changed from baseline to the last-observation-carried-forward endpoint at week 5 [19]. The study has been completed, and AFQ056 
showed a clinically relevant and significant antidyskinetic effect without changing the antiparkinsonian effects of dopaminergic therapy.

\section{BIIB014}

BIIB014 is a novel nondopaminergic drug that selectively antagonizes the adenosine $\mathrm{A}_{2 \mathrm{~A}}$ receptor. A phase II study was designed to explore the safety of BIIB014 and how well BIIB014 was tolerated when given at different doses to patients with early-stage PD. A total of 38 patients of both sexes were recruited for this study and randomly distributed in a double-blind fashion to receive either BIIB014 or placebo. The study has been completed, indicating good tolerance and showing dose-dependent, clinically relevant results in these patients [20].

\section{SR57667B (Paliroden)}

SR57667B acts by inhibiting acetylcholinesterase and by impairment of $\beta$-amyloid formation in $\mathrm{PD}$ patients. A multicenter randomized parallel-group double-blind phase II study was designed to assess the effect ofSR57667B at the dose of $4 \mathrm{mg} /$ day on the progression of parkinsonian symptoms in patients with early PD. The primary outcome measure was the time until the progression of the disability warranted the initiation of levodopa or dopamine agonist treatment, and the secondary outcome measures included assessments of symptoms, activities of daily living and global clinical status. The study has been completed, and SR57667B was shown to cause a significant decline in PD symptoms [21].

\section{Pioglitazone}

Pioglitazone selectively stimulates the nuclear receptor peroxisome proliferator-activated receptor- $\gamma$ (PPAR- $\gamma$ ) and, to a lesser extent, PPAR- $\alpha$. A preclinical study on an MPTP mouse model of PD showed that pioglitazone reduces the dopaminergic nerve cell death in the substantia nigra pars compacta and helps in reducing parkinsonian symptoms [22].

The following multicenter double-blind placebo-controlled phase II clinical trial of two doses of oral pioglitazone (15 and $45 \mathrm{mg}$ ) was designed for safety, tolerability and futility studies. Subjects who have been on a stable dosage of rasagiline $1 \mathrm{mg}$ /day or selegiline $10 \mathrm{mg} /$ day for at least 8 weeks but no more than 8 months will be randomized to one of the two doses of oral pioglitazone or matching placebo. The study will measure disease progression by the change in total UPDRS score between the baseline visit and 44 weeks. The study is active, even though the recruitment of participants has not started yet [23].

\section{CEP-1347 (KT7515)}

CEP-1347 (KT7515) is an antiapoptotic drug. It enhances neuronal survival in a variety of nonclinical models and was found to be safe and well tolerated in PD [24].

A randomized double-blind placebo-controlled dosefinding phase II study was conducted in approximately 800 participants to establish its safety and to determine an efficacious dose of CEP-1347 for the treatment of PD. Safety and tolerability were assessed by the number of participants experiencing adverse events. The study was terminated as CEP-1347 did not cause any significant decline in the progression of PD [25].

\section{Topiramate}

Topiramate is an AMPA glutamate antagonist. A preclinical examination of topiramate in an MPTP-lesioned marmoset model of PD showed a significant decline in LID [26].

A phase II double-blind trial to evaluate the effect of topiramate on LID in PD patients was designed. The patients were randomized to receive tablets of placebo or topiramate in a double-blind crossover design using randomization tables. Following the completion of the first arm of the study and the tapering and washout phases, the patients received topiramate or placebo in a crossover design for the same treatment duration. The dose of topiramate was slowly escalated twice each week as tolerated. If a patient could not tolerate the higher dose, it was reduced to the previously tolerated dose. The study was terminated due to slow recruitment of participants [27].

\section{Pardoprunox (SLV-308)}

Pardoprunox is a new partial dopamine agonist being developed for PD. A multicenter randomized doubleblind pramipexole-controlled parallel-group study of pardoprunox and pramipexole as adjunctive treatment to levodopa was designed.

Approximately 44 patients were randomized at a 3:1 ratio to two possible treatment groups, pardoprunox and pramipexole. The first part of the study was blinded and consisted of a minimum 1-week screening period, a 4-week switch and stabilization period and an 8-week maintenance period. The second part of the study was an open-label pardoprunox treatment with a dose adjustment period of 4 weeks followed by long-term maintenance treatment. There was a high dropout rate of participants due to adverse events (primarily nausea, somnolence and dizziness); thus, the study was terminated [28]. 


\section{Phase III Trials}

Phase III trials are generally designed to assess the effectiveness of a new intervention and, thereby, its value in clinical practice. They are randomized controlled multicenter trials in large patient groups (300-3,000 or more depending upon the disease/medical condition studied) and are aimed at being the definitive assessment of how effective a drug is in comparison with current 'gold-standard' treatment (table 3 ).

\section{EMD 1195686 (Safinamide)}

Safinamide is a monoamine oxidase B (MAO-B) inhibitor, reducing the degradation of dopamine, and a glutamate release inhibitor. It also inhibits dopamine reuptake. Additionally, safinamide blocks sodium and calcium channels. Various in vitro models showed that safinamide has neuroprotective and neurorescuing effects [29].

A total of 965 subjects were enrolled in a phase III clinical study to evaluate the long-term safety and tolerability of safinamide in PD patients. All the subjects first received $50 \mathrm{mg} /$ day of safinamide, with an increase in the target dose to $100 \mathrm{mg} /$ day after 14 days of a taper period until the end of the treatment. In case of any intolerance, the daily dose of $100 \mathrm{mg}$ was decreased to $50 \mathrm{mg}$ [30]. The study has been completed, and its results are extremely encouraging, with a significant improvement in the motor symptoms of LID. Based on its efficacy and the reduced side effect profile of safinamide, it can be used as a novel addition to the currently available therapeutic options for PD patients.

\section{ADS-5102 (Nurelin)}

ADS-5102 (Nurelin) is a proprietary formulation of amantadine in development for the treatment of central nervous system disorders including LID in PD patients. A phase III randomized double-blind placebo-controlled 4-arm parallel-group study was designed to evaluate the tolerability and efficacy of each of three dose levels of ADS-5102 oral capsules, an extended-release formulation of amantadine, dosed once daily for the treatment of LID in subjects with PD. The novel pharmacokinetic profile of ADS-5102 was expected to achieve higher amantadine plasma concentrations during daytime hours, when dyskinesia as well as motor and nonmotor symptoms of PD are most problematic, and low amantadine plasma concentrations overnight, which may reduce the sleep disturbances and occasional vivid dreams.

Advances in Drug Development for PD: Present Status
The study has recently been completed, and the results from the EASED (Extended Release Amantadine Safety and Efficacy Study in Levodopa-Induced Dyskinesia) trial were presented at the 17th International Congress of Parkinson's Disease and Movement Disorders on June 18, 2013, in Sydney, Australia [31]. ADS-5102 caused a significant reduction in the duration and severity of troublesome dyskinesia among PD patients. The encouraging data from this trial indicate that ADS-5102 has the potential to positively impact the lives of PD patients, and Adamas Pharmaceuticals is moving forward with new drug application activities.

\section{IPX066}

IPX066 is a dopamine receptor stimulant. A randomized placebo-controlled fixed-dose parallel-arm study of three doses of IPX066 versus placebo was designed to examine its efficacy as compared with placebo in PD. Approximately 350 subjects aged 30 years and older were equally randomized and received one of three doses (145, 245 or $390 \mathrm{mg}$ ) of IPX066 or matching placebo orally.

The study duration was approximately 30 weeks for each subject. The trial was completed, with the positive results demonstrating that IPX066 produced a significant improvement in the control of motor symptoms in subjects with advanced PD with potential benefits including a decreased off time (time to reappearance of the symptoms in between doses when levodopa's effects wear off) and a reduced levodopa dosing frequency [32].

\section{SCH 420814 (Preladenant)}

SCH 420814 (preladenant) is a drug developed by Schering-Plough which acts as a potent and selective antagonist of adenosine $\mathrm{A}_{2 \mathrm{~A}}$ receptor. Positive results were reported in a phase II clinical trial in humans with respect to its safety and efficacy [33].

A phase III 40-week active-controlled double-blind double-dummy extension study of preladenant in subjects with moderate-to-severe PD was designed to assess its safety and characterize its efficacy; data were collected for up to 52 weeks from these patients. Due to lack of efficacy and safety as compared with placebo, the study was terminated [34].

\section{Caffeine}

Caffeine can improve the motor deficits in PD similarly to adenosine $\mathrm{A}_{2 \mathrm{~A}}$ receptor antagonists such as istradefylline, which reduces off time and dyskinesia associated with standard dopamine replacement treatments. 
Table 3. Drugs in phase III clinical trials for the treatment of PD

\begin{tabular}{|c|c|c|c|c|c|}
\hline No. & $\begin{array}{l}\text { Drug name/ClinicalTrial.gov registration } \\
\text { No. and molecular structure }\end{array}$ & $\begin{array}{l}\text { Sponsor/ } \\
\text { investigator }\end{array}$ & $\begin{array}{l}\text { Mechanism } \\
\text { of action }\end{array}$ & $\begin{array}{l}\text { Route of } \\
\text { administration }\end{array}$ & Comments/status \\
\hline 1 & $\begin{array}{l}\text { EMD } 1195686 \text { Safinamide/ } \\
\text { NCT00865579 }\end{array}$ & EMD Serono & $\begin{array}{l}\text { Inhibits MAO-B } \\
\text { and glutamate } \\
\text { release and is a } \\
\text { dopamine reuptake } \\
\text { blocker }\end{array}$ & Oral & Completed \\
\hline 2 & $\begin{array}{l}\text { ADS-5102 (extended release } \\
\text { amantadine } \mathrm{HCl} \text { )/NCT01397422 }\end{array}$ & $\begin{array}{l}\text { Adamas } \\
\text { Pharmaceuticals } \\
\text { Inc. }\end{array}$ & $\begin{array}{l}\text { Stimulation of } \\
\text { dopamine receptors }\end{array}$ & Oral & Completed \\
\hline 4 & $\begin{array}{l}\text { Preladenant and rasagiline/ } \\
\text { NCT01215227 }\end{array}$ & Merck & $\begin{array}{l}\text { Adenosine } \mathrm{A}_{2 \mathrm{~A}} \\
\text { antagonist }\end{array}$ & Oral & $\begin{array}{l}\text { Terminated due } \\
\text { to lack of efficacy } \\
\text { vs. placebo }\end{array}$ \\
\hline 7 & E2007/NCT00360308 & Eisai Ltd. & $\begin{array}{l}\text { Selective } \\
\text { noncompetitive } \\
\text { AMPA-type } \\
\text { glutamate receptor } \\
\text { antagonist }\end{array}$ & Oral & $\begin{array}{l}\text { Terminated due } \\
\text { to lack of efficacy } \\
\text { vs. placebo }\end{array}$ \\
\hline 8 & Rasagiline/NCT01187888 & $\begin{array}{l}\text { Ludwig } \\
\text { Maximilian } \\
\text { University of } \\
\text { Munich }\end{array}$ & MAO-B inhibitor & Oral & $\begin{array}{l}\text { Terminated due } \\
\text { to lack of } \\
\text { eligible patients }\end{array}$ \\
\hline
\end{tabular}


Table 4. Neuroprotective agents in PD

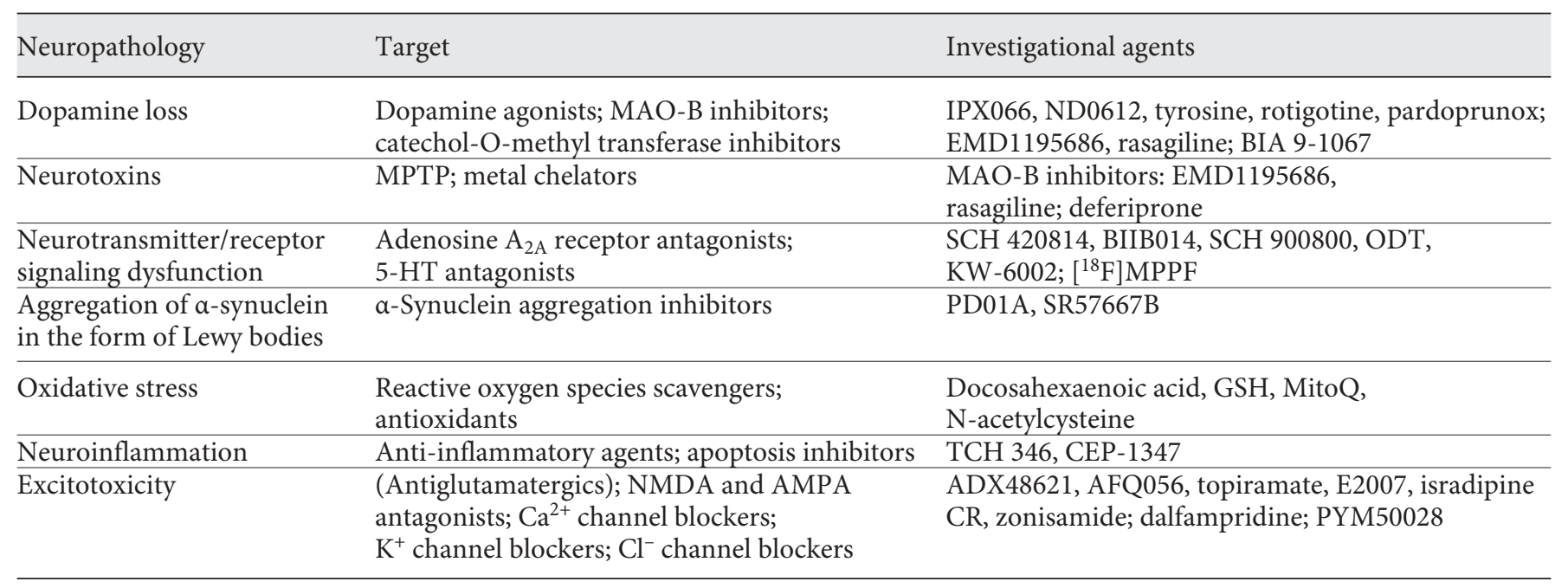

Recent studies have consistently found that people who do not use caffeine are at higher risk of developing PD.

This study was designed to evaluate the efficacy of caffeine $200 \mathrm{mg}$ twice daily versus matching placebo for motor and nonmotor aspects of the disease. It will be performed in three stages. In the first 6-month stage, medications will be held constant to see whether caffeine produces benefits regarding motor symptoms. Then, in a 4 -year extension stage, it will be established whether the effects of caffeine persist (or even increase) and whether caffeine helps reduce the doses of other PD medications and/or prevents their side effects. Finally, the trial will be finished with a 6-month stage, in which all the patients will be placed on caffeine treatment; this will allow to assess its use in later disease, but more importantly, it will assess whether early use of caffeine produces long-term changes beyond its immediate effects. This study has not yet started recruitment. It is estimated to be completed by February 2021 [35].

\section{Zonisamide}

Zonisamide is a sulfonamide anticonvulsant approved for use as an adjunctive therapy in adults with partialonset seizures and infantile spasm. The exact mechanism of action is not known. An open trial of zonisamide on 9 patients with PD showed positive results by lessening PD symptoms, especially wearing-off [36].

A phase III study was designed to investigate the neuroprotective effect of zonisamide in early PD. A total of 60 patients aged $45-85$ years with early PD who have met the study criteria will be enrolled and alternately randomized into two groups, based on their visit date. Demographic data, UPDRS scores, modified Hoehn and Yahr scale scores and modified Schwab and England Activities of Daily Living scale scores will be determined and registered for each patient. The patients of group A will be treated with zonisamide $50 \mathrm{mg} / \mathrm{day}$ for 12 months, and the other group with placebo for the same time period. The mentioned scores will be registered every 2 months for both groups by blinded neurologist. Also, regular blood tests will be performed to prevent drug adverse events. This study is not yet open for participant recruitment [37].

\section{E2007 (Perampanel)}

E2007 (perampanel) is a first-in-class, orally administered, highly selective noncompetitive AMPA-type glutamate receptor antagonist. A study was conducted to establish the efficacy of E2007. Following the completion of the first phase III study in 301 patients, a second phase III study was conducted in 302 patients in North America. The second phase III study was a 20 -week double-blind placebo-controlled trial comparing two doses ( 2 and 4 $\mathrm{mg}$ ) of perampanel with placebo. Compared with placebo, the results did not show a significant difference in efficacy; thus, the study was terminated [38].

\section{Rasagiline}

Rasagiline is a MAO-B inhibitor used in PD. Various in vitro and in vivo models of PD showed the beneficial effect of rasagiline in the treatment of PD $[39,40]$. A randomized double-blind study was designed to assess the safety and efficacy of the drug in patients aged 50-80 years. The study was terminated due to the unavailability of eligible patients [41]. 


\section{Discussion}

Currently available treatments for PD can effectively control the motor symptoms of the disease in the early stages, but they do not slow or halt the relentless progression of the disease. An explosion of discoveries during the past decade is now providing renewed hope of a therapy. A number of clinical studies have investigated numerous compounds with a enormous variety of mechanisms of action, and they are in different developmental stages (table 4). To make advancements in PD research, experts suggest that a wide array of individuals participate in clinical studies, ranging from subjects with PD (at all stages) to those without PD. The agents in phase I, II and III clinical trials of PD are shown in tables 1, 2 and 3, respectively. The agents that are in development have shown both affirmative and negative results. The recent failures of phase III trials after the positive phase II studies highlight the need for new guidelines in preclinical and clinical phases of drug development, such as the use of validated biomarkers and error management checklists for drug developers that can identify and control sources of error in each phase of a drug study. Another problem in the development of PD therapy is that designing selective compounds without undesirable and potentially toxic side effects is difficult, and reaching the stage of clinical testing can take many years.

As reviewed in this paper, several promising randomized controlled trials are in progress, and an increased collaboration between pharmaceutical companies and basic and clinical researchers has the potential to bring us closer to developing an optimum treatment for PD. Thus, new treatments that slow the underlying disease are desperately needed. It is too soon to predict the exact compound that will be the treatment option for PD.

\section{References}

1 Thomas B: Parkinson's disease: from molecular pathways in disease to therapeutic approaches. Antioxid Redox Signal 2009;9: 2077-2082.

2 Parkinson J: An essay on the shaking palsy. J Neuropsychiatry Clin Neurosci 1817;14:223236, discussion 222.

3 Skibinski G, Finkbeiner S: Drug discovery in Parkinson's disease: update and developments in the use of cellular models. Int J High Throughput Screen 2011;2011:15-25.

4 Thomas B, Beal F: Parkinson's disease. Hum Mol Genet 2007;16:R183-R194.

5 Hwang O: Role of oxidative stress in Parkinson's disease. Exp Neurobiol 2013;1:11-17.

6 Klucken J, Barth J, Kugler P, Schlachetzki J, Henze T, Marxreiter F, Kohl Z, Steidl R, Hornegger J, Eskofier B, Winkler J: Unbiased and mobile gait analysis detects motor impairment in Parkinson's disease. PLoS One 2013;8:e56956.

7 Chaudhuri KR, Healy DG, Schapira AHV: Non-motor symptoms of Parkinson's disease: diagnosis and management. Lancet Neurol 2006;5:235-245.

8 Sherer TB, Betarbet R, Greenamyre JT: Pathogenesis of Parkinson's disease. Curr Opin Investig Drugs 2001;2:657-662.

-9 Dexter DT, Jenner P: Parkinson disease: from pathology to molecular disease mechanisms. Free Radic Biol Med 2013;62:132144.

10 Gandhi S, Wood NW: Molecular pathogenesis of Parkinson's disease. Hum Mol Genet 2005;14(spec No):2749-2755.
11 Utsumi H, Okuma Y, Kano O, Suzuki Y, Iijima M, Tomimitsu H, Hashida H, Kubo S, Suzuki M, Nanri K, Matsumura M, Murakami $\mathrm{H}$, Hattori N: Evaluation of the efficacy of pramipexole for treating levodopa-induced dyskinesia in patients with Parkinson's disease. Intern Med 2013;52:325-332.

12 Schneider JS, Pope A, Simpson K, Taggart J, Smith MG, DiStefano L: Recovery from experimental parkinsonism in primates with GM1 ganglioside treatment. Science 1992; 256:843-846.

13 Pope-Coleman A, Tinker JP, Schneider JS: Effects of GM1 ganglioside treatment on preand postsynaptic dopaminergic markers in the striatum of parkinsonian monkeys. Synapse 2000;36:120-128.

14 GM1 ganglioside effects on Parkinson's disease. http://www.clinicaltrials.gov/ct2/show/ NCT00037830? term $=$ nct00037830\&rank $=1$.

15 Addex successfully completes ADX48621 phase I program. 2009. http://www.drugs. com/clinical_trials/addex-successfully-completes-adx 48621-phase-program-6659.html.

16 ADX48621 for the treatment of levodopa induced dyskinesia in patients with Parkinson's disease. http://www.clinicaltrials.gov/ ct2/show/NCT01336088? term $=$ nct 0133608 $8 \&$ rank $=1$.

17 A trial of MitoQ for the treatment of people with Parkinson's disease. http://www.clinicaltrials.gov/ct $2 /$ show $/$ NCT00329056?term $=$ nct00329056\&rank=1.
18 Gregoire L, Morin N, Ouattara B, Gasparini F, Bilbe G, Johns D, Vranesic I, Sahasranaman S, Gomez-Mancilla B, di Paolo T: The acute antiparkinsonian and antidyskinetic effect of AFQ056, a novel metabotropic glutamate receptor type 5 antagonist, in L-dopa-treated parkinsonian monkeys. Parkinsonism Relat Disord 2011;17:270-276.

19 Efficacy and safety of AFQ056 when combined with increased doses of L-dopa in Parkinson's disease patients with moderate-severe L-dopa induced dyskinesia. http://www. clinicaltrials.gov/ct2/show/NCT01092065?te rm=nct01092065\&rank=1.

20 Dose-finding safety study of BIIB014 in earlystage Parkinson's disease (MOBILE). http:// www.clinicaltrials.gov/ct2/show/NCT004427 80 ? term $=$ nct $00442780 \&$ rank $=1$.

21 Study of the effect of SR57667B on ${ }^{18} \mathrm{~F}$-dopa PET imaging in patients with Parkinson's disease. http://www.clinicaltrials.gov/ct2/show/ NCT00220272?term $=$ nct00220272\&rank $=1$.

22 Breidert T, Callebert J, Heneka MT, Landreth G, Launay JM, Hirsch EC: Protective action of the peroxisome proliferator-activated receptor-gamma agonist pioglitazone in a mouse model of Parkinson's disease. J Neurochem 2002;82:615-624.

23 Pioglitazone in early Parkinson's disease. http://www.clinicaltrials.gov/ct2/show/NCT 01280123?term $=$ nct01280123\&rank $=1$.

24 Eggert D, Dash PK, Gorantla S, Dou H, Schifitto G, Maggirwar SB, Dewhurst S, Poluektova L, Gelbard HA, Gendelman HE: Neuroprotective activities of CEP-1347 in models of neuroAIDS. J Immunol 2010;184:746-756. 
25 Safety and efficacy study of CEP-1347 in the treatment of Parkinson's disease. http://www. clinicaltrials.gov/ct2/show/NCT00040404?te rm=nct00040404\&rank=1.

-26 Silverdale MA, Nicholson SL, Crossman AR, Brotchie JM: Topiramate reduces levodopainduced dyskinesia in the MPTP-lesioned marmoset model of Parkinson's disease. Mov Disord 2005;20:403-409.

27 Topiramate as a treatment for levodopa-induced dyskinesia in Parkinson's disease. http://www.clinicaltrials.gov/ct2/show/NCT 00296959? term $=$ nct00296959\&rank=1.

28 A pilot study to assess efficacy and safety of pardoprunox as adjunct therapy to L-dopa in the treatment of patients with Parkinson's disease experiencing motor fluctuations and dyskinesia. http://www.clinicaltrials.gov/ct2/ show/NCT00903838?term $=$ nct00903838\&ra $\mathrm{nk}=1$.

29 Caccia C, Maj R, Calabresi M, Maestroni S, Faravelli L, Curatolo L, Salvati P, Fariello RG: Safinamide: from molecular targets to a new anti-Parkinson drug. Neurology 2006; 67(suppl 2):S18-S23.
30 Open-label trial to determine the long-term safety of safinamide in Parkinson's disease patients. http://www.clinicaltrials.gov/ct2/show/ NCT00865579?term $=$ NCT00865579\&rank $=1$.

31 Extended release amantadine safety and efficacy study in levodopa-induced dyskinesia (EASED Study). http://www.clinicaltrials.gov/ ct2/show/NCT01397422?term $=$ nct01397422\& rank=1.

32 A study to evaluate the safety and efficacy of IPX066 in subjects with Parkinson's disease (APEX-PD). http://www.clinicaltrials.gov/ct2/ show/NCT00880620?term=NCT00880620\&ra $\mathrm{nk}=1$.

33 Hauser RA, Cantillon M, Pourcher E, Micheli F, Mok V, Onofrj M, Huyck S, Wolski K: Preladenant in patients with Parkinson's disease and motor fluctuations: a phase 2, doubleblind, randomised trial. Lancet Neurol 2011; 10:221-229.

34 An active-controlled extension study to P04938 and P07037 (P06153 AM3). http:// www.clinicaltrials.gov/ct2/show/NCT012152 27 ?term $=$ nct01215227\&rank $=1$.

35 Caffeine as a therapy for Parkinson's disease. http://www.clinicaltrials.gov/ct2/show/NCT 01738178 ? term $=$ nct $01738178 \&$ rank $=1$.

36 Murata M,HoriuchiE, Kanazawa I:Zonisamide has beneficial effects on Parkinson's disease patients. Neurosci Res 2001;41:397-399.
37 Study of zonisamide in early Parkinson disease (ZONIST). http://www.clinicaltrials. gov/ct2/show/NCT01766128?term $=$ nct017 66128\&rank=1.

38 Efficacy, safety and tolerability of E2007 in levodopa-treated Parkinson's disease patients with motor fluctuations. http://www.clinicaltrials.gov/ct2/show/NCT00360308?term $=$ nct 00360308\&rank=1.

39 Heikkila RE, Duvoisin RC, Finberg JP, Youdim MB: Prevention of MPTP-induced neurotoxicity by AGN-1133 and AGN-1135, selective inhibitors of monoamine oxidase- $\mathrm{B}$. Eur J Pharmacol 1985;116:313-317.

40 Akao Y, Maruyama W, Yi H, Shamoto-Nagai M, Youdim MB, Naoi M: An anti-Parkinson's disease drug, N-propargyl-1(R)-aminoindan (rasagiline), enhances expression of anti-apoptotic bcl-2 in human dopaminergic SH-SY5Y cells. Neurosci Lett 2002;326:105108.

41 Efficacy, tolerability and safety of azilect in subjects with progressive supranuclear palsy (PROSPERA). http://www.clinicaltrials.gov/ ct2/show/NCT01187888?term =NCT011878 $88 \&$ rank $=1$. 